contract holder for a given size of contract. Therefore, with increasing contract size, the PVM would reduce and where the contract was held by a body corporate or (pension scheme) opted out contract holder, the value would be ${ }^{1}$.
I would welcome a critical analysis of the above reasoning by those with a through working knowledge of this area of the business of dentistry.

Paul V Mc Crory via email.
1. NASDAL Goodwill Survey - NHS Practice Values continue to drop. Available online at: www.nasdal.org.uk/assets/ press-releases/NASDAL\%20Goodwill\%20Survey\%20 \%20NHS\%20Practice\%20Values\%20Drop\%2026-03-19. pdf (Accessed April 2019)

2. The mystery of Goodwill valuations - what is EBITDA? Available online at: www.aspd.co.uk/aspd-articles/the-mysteryof-goodwill-valuations-what-is-ebitda/ (Accessed April 2019).

\title{
TePe launches pilot recycling initiative
}

TePe has partnered with Cannon Hygiene Ltd to introduce a pilot recycling scheme for interdental brushes. The TePe Environmental Recycling Initiative (TERI) will provide dental patients and staff with the UK's first pilot recycling solution for interdental brushes.

As part of the scheme, used interdental

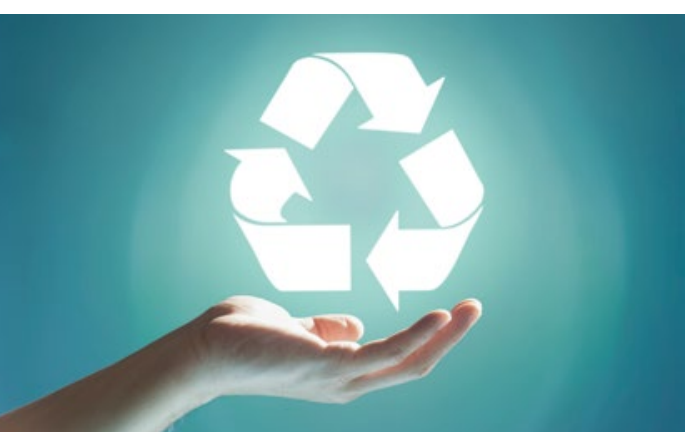

brushes can now be returned to the dental practice for recycling throughout the sixmonth pilot. The initiative marks a step change in the current disposal process, as it is not yet possible to recycle materials or products that are composed of more than one element in the UK. However, dental practices already have a solution in place to dispose of sharps and contaminated waste.

The TERI scheme will therefore utilise the existing system to dispose of interdental brushes in practice. This waste will then be incinerated to generate energy for heating and bottom ash for road and car park surfacing.

Elaine Tilling, TePe's Head of

Projects and Clinical Education, said: 'Plastics and other non-recyclable material are a prevalent issue for the dental profession and the wider dental industry. As a Swedish company, TePe has a long-standing and strong commitment to environmental protection and is constantly on the lookout for ways to reduce waste.

'The TERI pilot is about using an existing system for recycling products that would normally go into landfill. We have had a really enthusiastic response from dental practices wishing to take part in the pilot and we look forward to working with them to review the uptake over the coming months.'

There will be no cost incurred by the dental practices taking part in the scheme - TePe is simply calling on participating practices to ensure the disposal bin is placed in a prominent location to encourage patients and staff to make use of this facility.

\section{FGDP rejects CQC fee rise}

\section{The Faculty of General Dental Practice} (FGDP(UK)) has rejected the Care Quality Commission's $13 \%$ fee increase for dentists, which came into force last month.

The new fees will increase costs for single-location and domiciliary dental care providers by $£ 69-£ 149$, depending on the number of dental chairs, with fees for multiple-location providers rising by the same proportions.

While the Faculty supports the move to end the current cross-subsidy by dentists of other professions, it says it cannot understand how the regulator has arrived at its new cost estimates for inspecting dental surgeries given that dental providers have proved the lowest-risk sector it inspects.

Responding to the announcement, Ian Mills, the Faculty's Dean, said: 'The Faculty of General Dental Practice (UK) supports the maintenance and improvement of standards of care in dental practices, and recognises the contribution which the Care Quality Commission has made in helping to deliver this. In view of the highly positive reports the Commission has delivered on the dental sector in recent years, dentists will find a further increase in fees this year particularly bewildering and unwelcome. 'The cost increase is all the more surprising given the recent move from a comprehensive inspection model to a risk-based model. One would naively assume that such a shift would deliver a more cost effective means of delivering regulation, which should be reflected in the fees recouped from practices. The CQC has already claimed that it has realised significant cost efficiencies in its inspections, and as such it is extremely disappointing that the highly performing dental sector should in fact be faced with a marked increase in the cost of regulation.

Earlier this year, the FGDP rejected the fees at the proposal stage in response to a public consultation by the CQC. Its response is available at www.fgdp.org.uk/ policy-reports-and-consultations.

The full breakdown of CQC fees for 2019/20 is available at www.cqc.org.uk/ sites/default/files/20190326\%20Fees_ scheme_201920\%20fees_FINAL.pdf.

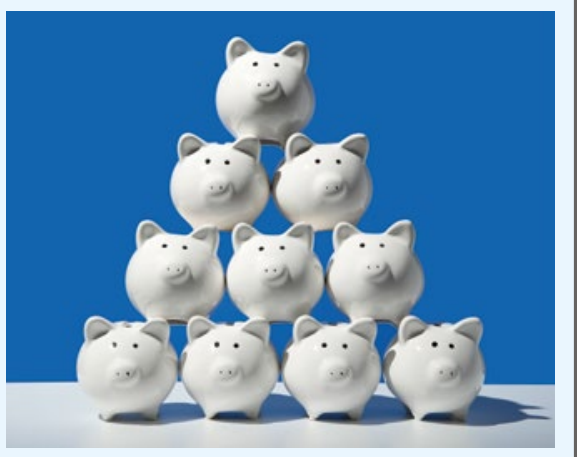

